STS/AATS/SCAI

Position

Statement

\title{
The clinical development of percutaneous heart valve technology
}

\section{A position statement of the Society of Thoracic Surgeons (STS), the American Association for Thoracic Surgery (AATS), and the Society for Cardiovascular Angiography and Interventions (SCAI)}

\section{Endorsed by the American College of Cardiology Foundation (ACCF) and the American Heart Association (AHA)}

Thomas A. Vassiliades, Jr, MD

Peter C. Block, MD

Lawrence H. Cohn, MD

David H. Adams, MD

Jeffrey S. Borer, MD

Ted Feldman, MD

David R. Holmes, MD

Warren K. Laskey, MD

Bruce W. Lytle, MD

Michael J. Mack, MD

David 0. Williams, MD

\section{Preamble}

This joint position statement represents the combined efforts of four professional societies (Society of Thoracic Surgeons [STS], American Association for Thoracic Surgery [AATS], American College of Cardiology [ACC], and Society for Cardiovascular Angiography and Interventions [SCAI]), two government agencies (the U.S. Food and Drug Administration [FDA] and the Centers for Medicare and Medicaid Services [CMS]), and numerous industry representatives to assess the foreseeable directions of a class of emerging technologies being developed to enable the percutaneous treatment of cardiac valve dysfunction. Percutaneous heart valve technology (PHVT) is a less invasive means of treating valvular heart disease. The goals of the interdisciplinary group have been to establish cooperation, identify consensus and controversy, and formulate clinical guidelines for the continued development of PHVT.

\footnotetext{
This document was approved by the Society for Thoracic Surgeons, the American Association for Thoracic Surgery, and the Society for Cardiovascular Angiography and Interventions. This document was endorsed by the American College of Cardiology Foundation and the American Heart Association.

When citing this document, please use the following citation format: Vassiliades Jr. TA, Block PC, Cohn LH, Adams DH, Borer JS, Feldman T, Holmes DR, Laskey WK, Lytle BW, Mack MJ, Williams DO. The clinical development of percutaneous heart valve technology: a position statement of the Society of Thoracic Surgeons (STS), the American Association for Thoracic Surgery (AATS), and the Society for Cardiovascular Angiography and Interventions (SCAI). J Thorac Cardiovasc Surg 2005;129:970-6.

Multiple copies, modification, alteration, enhancement, and/or distribution of this document are not permitted without the express permission of the authoring societies. Please direct requests to dmarquis@sts.org.

Reprinted with permission from the Society of Thoracic Surgeons, the American Association for Thoracic Surgery, and the Society for Cardiovascular Angioplasty and Interventions.

This document will be co-published in the Annals of Thoracic Surgery, the Journal of the American College of Cardiology, and Catheterization and Cardiovascular Interventions.

J Thorac Cardiovasc Surg 2005;129:970-6

$0022-5223 / \$ 30.00$

Copyright (C) 2005 by the Society of Thoracic Surgeons, the American Association for Thoracic Surgery, and the Society for Cardiovascular Angiography and Interventions

doi:10.1016/j.jtcvs.2005.02.013
} 


\section{Process}

On April 22, 2004, the STS/AATS Committee/Workforce for the Assessment of New Technology (Appendix 1) organized a workshop on PHVT. Included were representatives from the STS, the AATS, the ACC, and SCAI. Also in attendance were representatives from the FDA's Division of Cardiovascular Devices, Circulatory Support and Prosthetic Devices Branch, CMS, and industry representatives (Appendix 2). Clinical aspects of PHVT were initially addressed in small groups with representatives from each of the constituencies followed by a summary report and discussion amongst the entire group. All participants of the workshop and writing group members completed a disclosure questionnaire documenting all outside relationships that might be perceived as real or potential conflicts of interest. ${ }^{1}$ Current crucial issues addressed were: 1) trial design, 2) control groups, 3) end points for assessment, 4) rate of technological change, 5) institutional and investigator requirements, and 6) safety. Consideration of these issues is undertaken with the acknowledgement that for most patients with heart valve disease, open cardiac surgical procedures provide an established form of treatment.

\section{Background}

For decades, percutaneous interventional therapy has been an option for patients with pulmonic, ${ }^{2-4}$ mitral, ${ }^{5,6}$ and aortic valvular disease. ${ }^{7,8}$ For selected patients with pulmonic or mitral stenosis, percutaneous valvuloplasty is the treatment of choice. ${ }^{9,10}$ For patients with calcific aortic stenosis, balloon aortic valvuloplasty (BAV) $)^{11,12}$ has been used as a bridge to aortic valve replacement as noted by the current ACC/American Heart Association (AHA) guidelines. ${ }^{13}$ Hospital mortality for BAV varies from $3.5 \%$ to $13.5 \%$, and as many as $25 \%$ of the patients have at least one serious complication. ${ }^{14}$ The durability of BAV is limited. Therefore, open aortic valve replacement remains the definitive therapy for aortic stenosis in patients who are viable candidates for surgery.

Currently, multiple new concepts for the percutaneous treatment of valvular heart disease are under evaluation in a variety of stages from bench testing to early clinical trials. ${ }^{15}$ Most involve either mitral valve repair via annular or leaflet manipulation, or percutaneous valve insertion for pulmonic or aortic valve disease. Using a stent-based valve, ${ }^{16,17}$ percutaneous pulmonary valve insertion has been successfully carried out in more than 60 cases, primarily outside the U.S., usually for the treatment of conduit stenosis. ${ }^{18}$ However, late follow-up is limited and future trials will need to focus on the issues of patient selection with degenerated conduits, durability and the inability of the device to grow. Although percutaneous aortic valve insertion has been carried out on a compassionate use for extremely high-risk patients, ${ }^{19,20}$ significant para-valvular regurgitation and early mortality characterize the experience thus far. ${ }^{21} \mathrm{Cur}-$ rently, there are no approved percutaneous aortic valve devices in the U.S.

The goal of the following discussion is to provide a framework for clinical research directed at further testing of PHVT.

\section{General Guidelines Regarding Clinical Trial Design for PHVT}

The testing of new medical technology usually begins with bench testing (in vitro) and in vivo animal testing, followed by clinical investigation. Initial clinical investigation begins with a feasibility study: a small, unblinded, and uncontrolled trial designed to test safety. Following the feasibility trials, a larger, prospective, controlled trial is performed to evaluate both safety and efficacy (Pivotal trial). The most rigorous design for establishing the safety and effectiveness of new technology is the controlled, randomized trial. It is the consensus of the participants of the Workshop that no adequate historical controls exists for the evaluation of PHVT sufficient to eliminate the influence of confounding variables. Therefore, randomized controlled trials are necessary to evaluate safety and efficacy properly for these devices.

At each institution participating in clinical trials, the study team should include at least an interventionalist, a cardiac surgeon, a non-interventional clinical investigator charged with monitoring patient welfare, and an echocardiographer. All members of the study team should be charged with ensuring proper patient selection to achieve safety and objectivity. Furthermore, such collaborative interaction will aid trial completion and, it is hoped, lead to improvement in device placement, function, and assessment.

Use of PHVT requires skill sets independent of the operator's base discipline, and specific training should be required before engaging in any percutaneous valve procedure. Those individuals eligible for the procedural training should be confined to experienced interventionalists and surgeons. Feasibility studies in adults should be restricted to a small number of high-volume cardiology and cardiac surgery programs where at least 100 to 150 surgical valve operations per year are performed. ${ }^{22}$ Participating cardiac surgeons should perform a minimum of 40 to 50 valve repairs or replacements annually. ${ }^{23}$ In addition, the surgeon's valve experience should be specific for the device under consideration (i.e., a surgeon with a large volume of aortic valve replacement and minimal mitral valve repair would only qualify for an aortic device study). Although most interventionalists are likely to be cardiologists, or rarely interventional radiologists, surgeons with appropriate training in percutaneous procedures may directly participate, in addition to providing patient selection, guidance, and back-up services. Interventionalists should perform at least 100 percutaneous procedures each year, and have 
TABLE 1. Randomized controlled trial designs

\begin{tabular}{|c|c|c|}
\hline Trial design type & $\begin{array}{c}\text { Null hypothesis for } \\
\text { effectiveness }\end{array}$ & $\begin{array}{c}\text { Alternate } \\
\text { hypothesis for } \\
\text { effectiveness }\end{array}$ \\
\hline Superiority & $\begin{array}{l}\text { Treatment } A \text { success } \\
\text { rate } \leq \text { treatment } B \\
\text { rate }\end{array}$ & $\begin{array}{l}\text { Treatment } A \text { success } \\
\quad \text { rate }>\text { treatment } B \\
\quad \text { rate }\end{array}$ \\
\hline Non-inferiority & $\begin{array}{l}\text { Treatment A success } \\
\quad \text { rate } \geq \text { treatment } B \\
\text { rate }+ \text { "delta" }\end{array}$ & $\begin{array}{l}\text { Treatment } A \text { success } \\
\text { rate }<\text { treatment } B \\
\text { rate }+ \text { "delta" }\end{array}$ \\
\hline
\end{tabular}

experience with the catheter-based techniques required for PHVT (e.g., trans-septal and/or coronary sinus access techniques) and with the assessment and management of valvular heart disease. ${ }^{24-26}$ Clinical trials should also be limited to centers with a proven track record of close collaboration between the aforementioned disciplines and experience in trials.

A major problem with all new devices is how to evaluate a first-generation product against the established "gold standard," in this case the open cardiac surgical procedure. How should a new device that avoids cardiac surgery but perhaps is less effective-especially initially-be best evaluated? At the design stage of a clinical trial it is essential to state clearly the purpose of the study and the specific hypothesis to be evaluated. ${ }^{27}$ Randomized controlled trial designs can be broadly viewed as evaluating the superiority or noninferiority (clinical equivalence) of the test arm with regard to effectiveness. Critical differences exist between these two approaches, which affect sample size, study feasibility, and credibility of conclusions. ${ }^{28}$ It is important to point out that it is statistically, and practically, impossible to demonstrate equivalence between two treatment arms, as some differences are always likely to exist. Therefore, a "clinically acceptable" difference ("delta") between the two treatment arms must be specified at the outset and the null hypothesis constructed such that its rejection supports the claim of non-inferiority (Table 1).

Sample size estimation would be most appropriately determined by power calculations for the specific end point and study results published in the literature. Study end points should be chosen that can be assessed objectively by: 1) creating clear criteria for the outcome, 2) collecting the necessary documentation, and 3) having independent core laboratories, blinded to the treatment assignment, adjudicate the cases whenever possible. Meaningful outcome measurements could include components such as death, myocardial infarction, need for surgical repair (including the need for valve replacement when repair was the preoperative intent), stroke or embolic events, hemodynamic deterioration, ejection fraction, measures of reverse remodeling, valvular regurgitation, endocarditis, hemolysis, and functional testing.
Although the timing of end point measurements was discussed at the Workshop, the consensus was that it is too early in PHVT development to answer this question.

Finally, in any trial designed to evaluate an intervention, "crossovers" are likely to occur. Crossover patients can be analyzed using several methods, including "intent to treat," "as treated," and "per protocol". ${ }^{29,30}$ In addition, a large amount of missing end point data can make interpretation of trial results difficult and threaten the success of the trial. Every effort should be made to collect all data specified in the trial. Additionally, the importance of a knowledgeable and active Data Safety and Monitoring Board cannot be overemphasized. This board should be independent of the investigators, of the company sponsoring the trial, and of any contracted data analysis organizations involved in the trial.

\section{Percutaneous Mitral Valve Repair (PMVR) for Mitral Regurgitation}

The pathophysiologic triad describing mitral regurgitation (MR) is composed of etiology (cause of the disease), valve lesions (resulting from the disease), and valve dysfunction (resulting from the lesion). ${ }^{31}$ These distinctions are relevant because long-term prognosis depends on etiology, whereas surgical treatment strategy-and future PMVR-depends on valve dysfunctions and lesions. Mild to moderate MR is seen in approximately $20 \%$ of the general population. ${ }^{32,33}$ The most common causes of MR in Western countries are degenerative, ischemic, and dilated cardiomyopathy. ${ }^{34}$

The STS National Adult Cardiac Surgery Database 2003 notes a countrywide mortality for first time elective mitral valve repair of $2.5 \%$ (males) to $3.9 \%$ (females), and for mitral valve surgery combined with coronary artery bypass these figures are $6.1 \%$ (males) to $12.2 \%$ (females), respectively. ${ }^{35}$ Patients undergoing reoperation are also at increased risk. ${ }^{36}$ Mitral valve repair is considered superior to mitral valve replacement because of lower operative mortality, improved late survival, a reduced risk of endocarditis, fewer thromboembolic complications, and better preservation of left ventricular function. ${ }^{37-42}$ However, the majority of mitral valve operations done in the U.S. in 2003 remained mitral valve replacement. ${ }^{43}$ Individual surgeon experience remains the key factor in predicting the likelihood of mitral valve repair or replacement for any given patient.

To discuss patient selection for PMVR for MR and to consider comparative outcomes with surgical approaches, it is possible to consider two classifications: one focusing on etiology and the other on leaflet dysfunction, realizing that both can influence patient outcome. For the purposes of this discussion, we will focus on leaflet dysfunction as opposed to etiology. ${ }^{33}$ This classification is based on the opening and closing motions of the mitral leaflets. Patients with type I dysfunction have normal leaflet motion. Mitral regurgitation in these patients is due to annular dilatation or leaflet per- 
foration. There is increased leaflet motion in patients with type II dysfunction with the free edge of the leaflet overriding the plane of the annulus during systole (leaflet prolapse). The most common lesions responsible for type II dysfunction are chordal elongation or rupture and papillary muscle elongation or rupture. Patients with type IIIa dysfunction have restricted leaflet motion during both diastole and systole. The most common lesions are leaflet thickening/retraction, chordal thickening/shortening or fusion, and commissural fusion. The mechanism of MR in type IIIb dysfunction is restricted leaflet motion during systole: left ventricular enlargement with apical papillary muscle displacement due to ischemic or idiopathic cardiomyopathy causes this type of valve dysfunction.

Currently, there are two concepts for percutaneous mitral valve repair: 1) partial mitral annuloplasty by device placement in the coronary sinus to reduce the circumference of the posterior mitral annulus; and 2) anterior and posterior leaflet attachment using an edge-to-edge clip or suture. ${ }^{44-46}$ Posterior annuloplasty faces multiple anatomic challenges including dilation of the trigone-to-trigone area ${ }^{47,48}$ leaflet tethering by papillary muscle displacement, ${ }^{49}$ mitral annular calcification, inability to fix the annuloplasty to the fibrous trigones,${ }^{50}$ and the potential for compromise of the circumflex coronary artery. The edge-to-edge repair concept has been used in surgically treated patients, but the best results have been obtained when combined with an annuloplasty. ${ }^{51}$ The results of edge-to-edge repair have been suboptimal in patients with restricted leaflet motion (type III dysfunction), including a recent surgical series where it was used in combination with a posterior annuloplasty in patients with ischemic regurgitation. ${ }^{52}$

A feasibility study designed to evaluate PMVR with annular remodeling technology should consist of 20 to 30 patients with severe symptomatic MR caused by annular dilation with normal leaflet motion (type I dysfunction) or by restricted leaflet motion (type IIIb dysfunction), or by a combination of these two mechanisms. A feasibility study to evaluate PMVR with leaflet edge-to-edge repair should consist of 20 to 30 patients with excessive leaflet motion (type II dysfunction).

These studies will have safety as the primary end point and will assess adverse events including residual (equal or worse) MR, myocardial infarction, stroke, tamponade, coronary artery injury, death, and leaflet damage compromising subsequent mitral valve repair. The secondary end points of the study will include quantitative echocardiographic assessment of MR diminution, left ventricular function, and symptom status. The design of Pivotal trials will need to await safety and durability data from the feasibility study, but will include: 1) comparison of PMVR to open surgical mitral valve repair in patients with types I, II, and IIIb dysfunction; or 2) comparison of
PMVR to optimal medical therapy ${ }^{53}$ in non-surgical candidates with either end-stage cardiomyopathy and type IIIb severe MR or elderly patients with significant comorbidities and type II dysfunction.

\section{Percutaneous Aortic Valve Replacement (PAVR)}

Aortic valve replacement is the most common heart valve operation. Aortic stenosis (AS) affects from 2\% to 7\% of individuals older than 65 years in the U.S., a prevalence that will continue to increase as more people live to older ages. ${ }^{54,55}$ Aortic stenosis is consistently progressive, ${ }^{56-59}$ and because it occurs in an elderly age group it is often associated with comorbid risk factors and previous bypass surgery. ${ }^{60}$ The goals of therapy for patients with AS include both improvement of symptoms and prolongation of life. ${ }^{61}$ Percutaneous strategies for the treatment of AS began with percutaneous balloon valvuloplasty, but data from singlecenter studies and the multicenter National Heart, Lung, and Blood Institute (NHLBI) registry noted only a modest improvement in early hemodynamics, a substantial incidence of peripheral vascular complications, a 30-day mortality of $7 \%$, and a high incidence of restenosis within 6 months. ${ }^{7,62}$

The disappointing results of BAV have led to investigation of the possibility of percutaneous placement of prosthetic aortic valves. Such devices have been used clinically in a small number of cases in high-risk patients. ${ }^{63} \mathrm{~A}$ feasibility study designed to evaluate PAVR might consist of 20 to 30 patients with severe symptomatic AS (aortic valve area $\leq 0.70 \mathrm{~cm}^{2}$ ), or severe aortic valve regurgitation (AR). Initial feasibility trials have treated only AS patients because AR treatment is more problematic for the first generation of PAVR devices. Therefore, it is envisioned that feasibility trials will initially enroll only patients with severe AS.

In addition, differences in the age and comorbidity between patients with AS and AR dictate each study population be fairly pure, with a cohort of one or the other but not a mixture. These initial patients should be judged to be at extremely high operative risk as calculated by an established risk scoring system. ${ }^{64-67}$ Selection of a risk scoring system as well as the definition of inoperability should be clearly defined in the protocol. Such inoperability will almost always be caused by non-cardiac morbid conditions. In such a feasibility trial it is not acceptable to use such devices for patients who simply refuse open surgery on the basis of personal preference. Study end points will include death, stroke, myocardial infarction, para-prosthetic leak, device migration, symptom status, angiographic gradient, and rehospitalization. Pivotal trials will depend upon the safety data from the feasibility trial, and a variety of control groups may be possible including patients having balloon valvuloplasty and high-risk open surgery. 


\section{Minimally Invasive Valve Surgery}

The procedural goal of PHVT is to reliably repair or replace dysfunctional heart valves percutaneously and without the need for cardiopulmonary bypass (CPB). An alternate approach has been to repair or replace valves off-pump through small incisions, thereby simplifying device delivery. Concepts along these lines include anterior and posterior pads connected by a subvalvular cord designed to draw the posterior leaflet and annulus of the mitral valve toward the anterior leaflet ${ }^{68}$; a transatrial off-pump edge-to-edge mitral valve repair ${ }^{69}$; and off-pump AR antegrade through the ascending aorta or retrograde through the left ventricular apex. ${ }^{70}$ The minimally invasive surgical approach is an avenue of treating heart valve disease that not only has benefit on its own merit but also supports development of PHVT.

\section{Regulatory Considerations}

At this Workshop, the general considerations of the FDA, as expressed by Bram Zuckerman, Director of Cardiovascular Devices, Office of Device Evaluation (ODE), Center for Devices and Radiologic Health, were as follows. Percutaneous heart valve systems are considered class III devices; they will be reviewed as pre-market approval (PMA) applications $^{71}$ and, as such, controlled, randomized clinical trials will be the gold standard for meeting FDA requirements. Industry or independent study investigators should solicit the assistance and guidance of the FDA before designing any clinical trial for PHVT. ${ }^{72}$ Post-market approval studies may be required.

\section{Summary}

Although percutaneous devices for the repair or replacement of heart valves appear promising, they are clearly in an early stage of development. Many critical questions remain unanswered, including the durability of these devices and the potential adverse effects they may have on subsequent heart valve surgery. Therefore, one cannot justify the use of these experimental technologies in patients for whom published guideline indications do not exist or in situations of prophylactic therapy until data on safety and effectiveness are gathered from well-designed clinical trials. Study candidates should consist of symptomatic patients in whom long-term survival is already severely compromised. Such a strategy would allow the collection of mid-term device durability data while providing much needed clinically relevant safety and effectiveness data.

Prospective, randomized, clinical trials provide the most reliable evidence of the effectiveness of the treatment. Without such trials, ineffective treatments (or worse, harmful treatments) may be accepted in medical practice. Our collective enthusiasm for new, less-invasive cardiovascular approaches should not divert us from the importance of evaluating these devices in the context of a controlled clinical trial environment. Success of these clinical trials ultimately depends upon a sincere commitment to collaboration between cardiology and cardiac surgery.

\section{References}

1. The Society of Thoracic Surgeons Disclosure Policy and Guidelines Regarding Conflicts of Interest, 2002. Available at: www.sts.org. Accessed April 18, 2004.

2. Jarrar M, Betbout F, Rarhat MB, et al. Long-term invasive and non-invasive results of percutaneous balloon pulmonary valvuloplasty in children, adolescents, and adults. Am Heart J. 1999;138:950-4.

3. Kan JS, White RJ Jr., Mitchell SE. Percutaneous balloon valvuloplasty: a new method for treating congenital pulmonary valve stenosis. $N$ Engl J Med. 1982;307:540-2.

4. Kan JS, White RI, Mitchell SE. Percutaneous transluminal balloon valvuloplasty for pulmonary valve stenosis. Circulation. 1984;69:55460 .

5. Inoue K, Owaki T, Nakamura $\mathrm{T}$, et al. Clinical application of transvenous mitral commissurotomy by a new balloon catheter. $J$ Thorac Cardiovasc Surg. 1984;87:394-402.

6. Iung B, Garbarz E, Michaud P, et al. Late results of percutaneous mitral commissurotomy in a series of 1,024 patients. Analysis of late clinical deterioration: frequency, anatomic findings, and predictive factors. Circulation. 1999;99:3272-8.

7. NHLBI Balloon Valvuloplasty Registry Participants. Percutaneous balloon aortic valvuloplasty: acute and 30-day follow-up results in 674 patients. Circulation. 1991;84:2383-97.

8. Cribier A, Savin T, Saoudi N, et al. Percutaneous balloon aortic valvuloplasty of acquired aortic stenosis in elderly patients: an alternative to valve replacement? Lancet. 1986;1:63-7.

9. Palacios I, Block PC, Brandi S. Percutaneous balloon valvotomy for patients with severe mitral stenosis. Circulation. 1987;75:778-84.

10. Babic UU, Pejcic P, Dgurisiz Z. Percutaneous transarterial balloon valvuloplasty for mitral valve stenosis. Am J Cardiol. 1986;57:1101-4.

11. O'Neill WW. Predictors of long-term survival after percutaneous aortic valvuloplasty: report of the Mansfield Scientific Balloon Aortic Registry. J Am Coll Cardiol. 1991;17:193-8.

12. Sholler GF, Keane JF, Perry SB. Balloon dilation of congenital aortic valve stenosis: results and influence of technical and morphological features on outcome. Circulation. 1988;78:351-60.

13. Bonow RO, Carabello B, De Leon AC Jr., et al. ACC/AHA Task Force Report. J Am Coll Cardiol. 1998;32:1486-582.

14. McKay RG. The Mansfield Scientific Aortic Valvuloplasty Registry: overview of acute hemodynamic results and procedural complications. J Am Coll Cardiol. 1991;17:485-91.

15. Vahanian A, Palacios IF. Percutaneous approaches to valvular disease. Circulation. 2004;109:1572-9.

16. Wright KC, Wallace S, Charnasangavej C. Percutaneous endovascular stents: an experimental evaluation. Radiology. 1985;156:68-72.

17. Bonhoeffer P, Boudjemline Y, Saliba Z, et al. Transcatheter implantation of a bovine valve in pulmonary position: a lamb study. Circulation. 2000;102:813-6.

18. Bonhoeffer P, Boudjemline Y, Saliba Z et al. Percutaneous replacement of pulmonary valve in a right-ventricle to pulmonary-artery prosthetic conduit with valve dysfunction. Lancet. 2000;356:1403-5.

19. Cribier A, Eltchaninoff H, Bash A, et al. Percutaneous transcatheter implantation of an aortic valve prosthesis for calcific aortic stenosis: first human case description. Circulation. 2002;106:3006-8.

20. Eltchaninoff $\mathrm{H}$, Tron $\mathrm{C}$, Cribier A. Percutaneous implantation of aortic valve prosthesis in patients with calcific aortic stenosis: technical aspects. J Interv Cardiol. 2003;16:515-21.

21. Cribier A, Eltchaninoff H, Tron C, et al. Early experience with percutaneous transcatheter implantation of heart valve prosthesis for the treatment of end-stage inoperable patients with calcific aortic stenosis. J Am Coll Cardiol. 2004;43:698-703.

22. Petersen ED, Coombs LP, DeLong ER, et al. Procedure volume as a marker of quality for CABG surgery. JAMA. 2004;291:195-201. 
23. Crawford FA, Anderson RP, Clark RE, et al. Volume requirements for cardiac surgery credentialing: a critical examination of the ad hoc committee on cardiac surgery credentialing of the Society of Thoracic Surgeons. Ann Thorac Surg. 1996;61:12-6.

24. Advisory Council for Cardiothoracic Surgery, American College of Surgeons. Guidelines for standards in cardiac surgery. Bull Am Coll Surg. 1997;82:27-9.

25. Beller GA, Winters WL Jr., Carver JR, et al. Task force 3: Guidelines for Credentialing Practicing Physicians. American College of Cardiology 2000. Available at: www.acc.org. Accessed July 14, 2004.

26. Cameron AA, Laskey WK, Sheldon WC. SCAI Ad Hoc Task Force on Ethics in Invasive and Interventional Cardiology. Catheter Cardiovasc Interv. 2004;61:157-62.

27. Hulley SB, Cummings SR, Browner WS, et al. Designing Clinical Research. 2nd edition. Philadelphia, PA: Lippinicott Williams and Wilkins, 2001.

28. Friedman LM, DeMets DL, Furbeerg C. Fundamentals of Clinical Trials. 3rd edition. St. Louis, MO: Mosby-Year Book, 1996.

29. Newell D. Intention-to-treat analysis: implications for quantitative and qualitative research. Int J Epidemiol. 1992;21:837-41.

30. Senn SJ. The Design and Analysis of Crossover Trials. Chichester: Wiley, 1992.

31. Carpentier A. Cardiac valve surgery: the "French Correction." J Thorac Cardiovasc Surg. 1983;86:323-37.

32. Singh JP, Evans JC, Levy D, et al. Prevalence and clinical determinants of mitral, tricuspid, and aortic regurgitation (the Framingham Heart Study). Am J Cardiol. 1999;83:897-902.

33. Jones EC, Devereaux RB, Roman MJ, et al. Prevalence and correlates of mitral regurgitation in a population-based sample (the Strong Heart Study). Am J Cardiol. 2001;87:298-304

34. Otto CM. Evaluation and management of chronic mitral regurgitation. $N$ Engl J Med. 2001;345:740-6.

35. Society of Thoracic Surgeons Adult Cardiovascular National Database, Spring 2004 Executive Summary Contents. Available at: www. sts.org. Accessed August 23, 2004.

36. Edwards FH, Petersen ED, Coombs LP, DeLong ER, et al. Prediction of operative mortality following valve replacement surgery. J Am Coll Cardiol. 2001;37:885-92.

37. Cohn LH. Mitral valve repair for ischemic mitral regurgitation. $A d v$ Cardiol. 2002;39:153-6.

38. Enriquez-Sarano M, Schaff HV, Orszulak TA, et al. Valve repair improves the outcome of surgery for mitral regurgitation. Circulation. 1995;91:1022-8.

39. Jamieson WR, Edwards FH, Schwartz M, et al. Risk stratification for cardiac valve replacement. National Cardiac Surgery Database. Database Committee of the Society of Thoracic Surgeons. Ann Thorac Surg. 1999;67:943-51.

40. Yun KL, Miller DC. Mitral valve repair versus replacement. Cardiol Clin. 1991;9:315-27.

41. Grossi EA, Goldberg JD, LaPietra A, et al. Ischemic mitral valve reconstruction and replacement: comparison of long-term survival and complications. J Thorac Cardiovasc Surg. 2001;122:1107-24.

42. Gillinov M, Cosgrove DM, Blackstone EH, et al. Durability of mitral valve repair for degenerative disease. J Thorac Cardiovasc Surg. 1998;116:734-48.

43. Savage EB, Ferguson TB Jr., DiSesa VJ. Use of mitral valve repair: analysis of contemporary United States experience reported to the Society of Thoracic Surgeons National Cardiac Database. Ann Thorac Surg. 2003;75:820-5.

44. Fucci C, Sandrelli L, Pardini A, et al. Improved results with mitral valve repair using new surgical techniques. Eur J Cardiothor Surg. 1995;9:621-6.

45. Maisano F, Torraca L, Oppizzi M, et al. The edge-to-edge technique: a simplified method to correct mitral insufficiency. Eur J Cardiothor Surg. 1998;13:240-5.

46. Maisano F, Schreuder JJ, Oppizzi M, et al. The double-orifice technique as a standardized approach to treat mitral regurgitation due to sever myxomatous disease: surgical technique. Eur J Cardiothor Surg. 2000;17:201-5.
47. Heub AC, Jatene FB, Moreira LF, et al. Ventricular remodeling and mitral valve modifications in dilated cardiomyopathy: new insights from anatomic study. J Thorac Cardiovasc Surg. 2002;124:1216-24.

48. McCarthy PM. Does the intertrigonal distance dilate? Never say never. J Thorac Cardiovasc Surg. 2002;124:1078-9.

49. Calafiore AM, Gallina S, Di Mauro M, et al. Mitral valve procedure in dilated cardiomyopathy: repair or replacement? Ann Thorac Surg. 2001;71:1146-53

50. Gorman JH, Gorman RC, Jackson BM, et al. Annuloplasty ring selection for chronic ischemic mitral regurgitation: lessons from the ovine model. Ann Thorac Surg. 2003;76:1556-63.

51. Alfieri O, Maisano F, DeBonis M, et al. The double-orifice technique in mitral valve repair: a simple solution for complex problems. J Thorac Cardiovasc Surg. 2001;122:674-81.

52. Bhudia SK, McCarthy PM, Smedira NG, et al. Edge-to-edge (Alfieri) mitral repair: results in diverse clinical settings. Ann Thorac Surg. 2004;77:1598-606.

53. Bonow RO, Carabello B, de Leon AC, et al. ACC/AHA guidelines for the management of patients with valvular heart disease: executive summary. A report of the ACC/AHA Task Force on Practice Guidelines (Committee on Management of Patients With Valvular Heart Disease). J Heart Valve Dis. 1998;7:672-707.

54. Ross J Jr., Braunwald E. Aortic stenosis. Circulation. 1968;37 Suppl V:V61-7.

55. Horstkotte D, Logan F. The natural history of aortic valve stenosis. Eur Heart J. 1988;9 Suppl E:57-64.

56. Kennedy KD, Nishimura RA, Holmes DR, et al. Natural history of moderate aortic stenosis. J Am Coll Cardiol. 1991;17:313-9.

57. Pellika PA, Nishimura RA, Bailey KR, et al. The natural history of adults with asymptomatic, hemodynamically significant aortic stenosis. J Am Coll Cardiol. 1990;15:1018-20.

58. O'Keefe JH, Vliestra RE, Bailey KR, Holmes DR. The natural history of candidates for balloon aortic valvuloplasty. Mayo Clin Proc. 1987; 62:986-91.

59. Borer JS, Bonow RO. Contemporary approach to aortic and mitral regurgitation. Circulation. 2003;108:2432-8.

60. Scott WC, Miller DC, Haverich A, et al. Determinants of operative mortality for patients undergoing aortic valve replacement: discriminate analysis of 1,479 operations. J Thorac Cardiovasc Surg. 1985; 89:400-13.

61. Lytle BW, Cosgrove DM, Taylor PC, et al. Primary isolated aortic valve replacement: early and late results. J Thorac Cardiovasc Surg. 1989;97:675-94.

62. Block PC, Palacious IF. Comparison of hemodynamic results of antegrade versus retrograde percutaneous balloon aortic valvuloplasty. Am J Cardiol. 1987;60:659-62.

63. Boudjemline Y, Bonhoeffer P. Steps toward percutaneous aortic valve replacement. Circulation. 2002;105:775-8.

64. Edwards FH, Petersen ED, Coombs LP, et al. Prediction of operative mortality following valve replacement surgery. J Am Coll Cardiol. 2001;37:885-92

65. Parsonnet V, Dean D, Berstein AD. A method of uniform stratification of risk for evaluating the results of surgery in acquired adult heart disease. Circulation. 1989;79 Suppl I:I3-12.

66. Nashef SAM, Roques F, Michel P, et al. European system for cardiac operative risk evaluation (EuroSCORE). Eur J Cardiothorac Surg. 1997;91:667-84

67. Hattler BG, Madia C, Johnson C, et al. Risk stratification using the Society of Thoracic Surgeons program. Ann Thorac Surg. 1994;52: 1348-52.

68. Fukamachi K, Inoue M, Popovic ZB, et al. Off-pump mitral valve repair using the coapsys device: a pilot study in a pacing-induced mitral regurgitation model. Ann Thorac Surg. 2004;25:353-7.

69. Downing SW, Herzog WA, McLaughlin JS, et al. Beating-heart mitral valve surgery: preliminary model and methodology. J Thorac Cardiovasc Surg. 2002;123:1141-6.

70. Huber $\mathrm{CH}$, Nasratulla M, Augstburger M. Ultrasound navigation through the heart for off-pump aortic valved stent implantation: new tools for new goals. J Endovasc Ther. 2004;11:503-10.

71. Classify Your Medical Device. Device Advice. Available at: www. fda.gov/cdrh/deadvice/313.html. Accessed April 18, 2004. 
72. Early Collaborative Meetings Under the FDA Modernization Act (FDAMA): Final Guidance for Industry and CDRH Staff. Available at: www.fda.gov/cdrh/guidance/310.pdf. Accessed April 18, 2004.

\section{Appendix 1}

New Technology Assessment Committee Roster: Bruce W. Lytle, MD (Chair), W. Randolph Chitwood, Jr., MD, Lawrence H. Cohn, MD (Co-Chair, Taskforce on Percutaneous Valve Technology), Robert W. Emery, MD, James D. Fonger, MD, Larry R. Kaiser, MD, Rodney J. Landreneau, MD, Michael J. Mack, MD, Patrick M. McCarthy, MD, Bruce A. Reitz, MD, Julie A. Swain, MD, and Thomas A. Vassiliades, Jr., MD (Co-Chair, Taskforce on Percutaneous Valve Technology).

\section{Appendix 2}

"Key Issues in the Development in Percutaneous Heart Valve Technology" Workshop attendees: representing the STS and AATS: David H. Adams, MD, Lawrence H. Cohn, MD, James D. Fonger, MD, Karl H. Krieger, MD, Bruce W. Lytle, MD, Michael J. Mack, MD, Patrick M. McCarthy, MD, Valavanur A. Subramanian, MD, Julie A. Swain, MD, Thomas A. Vassiliades, Jr., MD; representing the SCAI: Peter C. Block, MD, Ted E. Feldman, MD; representing the ACC: Jeffrey S. Borer, MD, Robert O. Bonow, MD, David R. Holmes, MD, Richard E. Kuntz, MD, Warren K. Laskey, MD, Michael H. Sketch, MD, David O. Williams, MD, Michael J. Wolk, MD, Janet S. Wright, MD; representing the FDA and CMS: Dina Fleischer (FDA), Steven B. Kurtzman, MD (FDA), Wolf Sapirstein, MD (FDA), Bette Lemperle, RN, MPH
(FDA), Lori Paserchia (CMS), Bram Zuckerman, MD (FDA); representing Medical Device Industry: Cardiac Dimensions, Inc. (Kirkland, WA), Mary Norton, VP Regulatory Affairs, David Reuter, MD, Chief Medical Officer; Edwards Lifesciences, LLP, (Irvine, CA): Larry Wood, VP/GM PVI, Stanton Rowe, President PVI; Evalve, Inc. (Redwood City, CA): Ferolyn T. Powell, CEO, Liz McDermott, VP Regulatory and Clinical Affairs; ev3, Inc. (Plymouth, MN), Ginny Kirby, VP, Clinical Affairs, Stacing Enxing Seng; 3F Therapeutics, Inc., (Lake Forest, CA): R. C. Quijano, $\mathrm{MD}, \mathrm{PhD}$, Chief Technical Officer, Walter A. Cuevas, President and CEO; Guidant Corp., (Santa, Clara, CA): Beverly H. Lorell, MD, FACC, VP, Chief Medical and Technical Officer; Heart Leaflet Technologies, Inc., (Roseville, MN): Robert F. Wilson, CEO, Kem Schankereli, Director of Valve Development; Medtronic, Inc., (Minneapolis, MN): Jan Champion, Director, Regulatory/Clinical, Vickie Conley, Director, Business Development; Myocor, Inc., (Maple Grove, MN): C.J. Schweich, MD, CTO, Dan Mans, VP, Clinical and Regulatory Affairs; Viacor, Inc., (Wilmington, MA) Jonathan M. Rourke, COO, A. Marc Gillinov, MD, Clinical Advisor.

\section{Appendix 3}

Dr. Vassiliades is a consultant with Guidant. Dr. Block is affiliated with Evalve, Corvalve. Dr. Adams is a consultant with Edwards Lifesciences and 3F. Dr. Lytle owns 1,000 shares of stock in Johnson and Johnson. Dr. Mack is a consultant with Edwards Lifesciences and Medtronic. Drs. Cohn, Borer, Feldman, Holmes, Laskey, and Williams report no conflicts of interest. 